\begin{tabular}{lllll}
\multicolumn{5}{l}{ Abstract 0-021 Table 1 } \\
\hline & $\mathrm{S}+\mathrm{B}(131)$ & $\mathrm{S}(134)$ & $\mathrm{OR}(95 \% \mathrm{Cl})$ & $\mathrm{P}$ \\
\hline B. W.(g) & $882 \pm 249$ & $935 \pm 283$ & & 0.81 \\
G. A (wks) & $26.5 \pm 2.2$ & $26.8 \pm 2.2$ & & 0.91 \\
Age study (hrs) & $2.0 \pm 1.5$ & $1.8 \pm 1.6$ & & 0.85 \\
Death & $17 / 131(13 \%)$ & $22 / 134(16 \%)$ & $0.76(0.38,1.51)$ & 0.54 \\
BPD & $38 / 131(29 \%)$ & $67 / 134(50 \%)$ & $0.49(0.29,0.81)$ & 0.008 \\
BPD or death & $55 / 131(42 \%)$ & $89 / 134(66 \%)$ & $0.45(0.27,0.73)$ & 0.001 \\
BPD $^{*}$ & $57 / 131(44 \%)$ & $88 / 134(66 \%)$ & $0.4(0.25,0.66)$ & $<0.001$ \\
BPD $^{*}$ or death & $74 / 131(56 \%)$ & $110 / 134(82 \%)$ & $0.28(0.06,0.49)$ & $<0.001$ \\
mild $^{*}$ & $19 / 131(15 \%)$ & $21 / 134(16 \%)$ & $0.91(0.47,1.79)$ & 0.79 \\
mod $^{*}$ & $26 / 131(20 \%)$ & $41 / 134(31 \%)$ & $0.56(0.32,0.99)$ & 0.048 \\
severe* & $12 / 131(9 \%)$ & $26 / 134(19 \%)$ & $0.42(0.20,0.87)$ & 0.017 \\
\hline
\end{tabular}

Background/aims Intra-tracheal instillation of surfactant/budesonide significantly improves pulmonary status in animals. The aim is to investigate if this therapy would decrease the incidence of BPD or death.

Methods and materials This randomised controlled trial comprised 265 VLBW infants who had: 1) severe radiographic RDS, 2) requirement of IMV $\left(\mathrm{FIO}_{2} \geq 0.5\right)$ shortly after birth: 131 received survanta (S) $(100 \mathrm{mg} / \mathrm{kg})$ and budesonide (B) $(0.25 \mathrm{mg} / \mathrm{kg})(\mathrm{S}+\mathrm{B}$ gr. $)$, 134 received S only $(100 \mathrm{mg} / \mathrm{kg})(\mathrm{S}$ gr). The sample size was determined based on the hypothesis that $60 \%$ of infants in the $S$ group and $40 \%$ in the $\mathrm{S}+\mathrm{B}$ group would die or develop BPD defined at 34 weeks postm. age.

Results The S+B infant had lower tracheal aspirate interleukins 1, 6 and 8 , lower OI, lower MAP in the early course of therapy, higher chance to wean to room air $(\mathrm{p}=0.03)$. No significant immediate and long term adverse effects were observed. * NIH criteria

Conclusions In VLBW infants with severe RDS, administration of surfactant/budesonide significantly decreases the incidence of BPD and BPD or death with no apparent adverse side effects.

\section{0-022 TREATMENT OF VENTILATED PRETERM (PT) INFANTS WITH LATE SURFACTANT DOES NOT INCREASE SURVIVAL WITHOUT BRONCHOPULMONARY DYPLASIA (BPD) AT 36 WK PMA}

${ }^{1}$ RA Ballard, ${ }^{1}$ RL Keller, ${ }^{2}$ DM Black, ${ }^{1} \mathrm{PL}$ Ballard, ${ }^{3} \mathrm{~J}$ Asselin, ${ }^{4} \mathrm{EC}$ Eichenwald, ${ }^{5} \mathrm{M}$ Mammel, ${ }^{6}$ J Merrill, ${ }^{7} \mathrm{R}$ Ryan, ${ }^{8} \mathrm{R}$ Steinhorn, ${ }^{9} \mathrm{~W}$ Truog, ${ }^{10} \mathrm{~A}$ Tolsurf Study Group. ${ }^{1}$ Pediatrics, University of California San Francisco, San Francisco, USA; ${ }^{2}$ Epidemiology and Biostatistics, University of California San Francisco, San Francisco, USA; ${ }^{3}$ Pediatrics, Children's Hospital Oakland, Oakland California, USA; ${ }^{4}$ Pediatrics, University of Texas, Houston, USA; ${ }^{5}$ Pediatrics, Children's Hospitals and Clinics of Minnesota, St Paul, USA; ${ }^{6}$ Pediatrics, Children Hospital Oakland, Oakland California, USA; ${ }^{7}$ Pediatrics, Medical University of South Carolina, Charleston, USA; ${ }^{8}$ Pediatrics, University of California Davis, Davis, USA; ${ }^{9}$ Pediatrics, Children's Mercy Hospital, Kansas City MO, USA; ${ }^{10}$ Pediatrics, University of California San Francisco, San Francisco California, USA

\subsection{6/archdischild-2014-307384.91}

Background/aims The pathogenesis of BPD is multifactorial. In preterm infants $\leq 28$ wk GA requiring ventilation at 7-14 days, $>60 \%$ have surfactant dysfunction. Survival without BPD in these infants is $<25 \%$. Inhaled nitric oxide (iNO) may improve outcome in some infants (Schreiber, NEJM 2003, Ballard NEJM, 2006).

Methods Preterm infants $\leq 28$ wk GA requiring mechanical ventilation at 7-14 days were enrolled in a RCT at 25 US centres. All infants received iNO and were randomised to receive surfactant (Infasurf) or sham instillation behind a screen every 1-2 days; maximum of 5 doses. Infants were evaluated by physiologic oxygen/flow reduction at 36 and 40 wk. Pulmonary outcome to 18 months is being collected.

Results Between January 2010 and September 2013, 511 of the planned 524 infants were enrolled. There was no difference between groups in mean BW $(701 \pm 164$ grams), GA $(25.2 \pm$ $1.2 \mathrm{wk})$, percentage under $26 \mathrm{wk}(70.6 \%)$, race, gender, severity of disease at enrollment or co-morbidities of prematurity. Survival without BPD was not different between treated vs. controls at $36 \mathrm{wk}(31.3 \%$ vs.31.7\%; relative benefit $0.98(0.75,1.28 \mathrm{p}=$ $0.89)$ or $40 \mathrm{wk}(58.7 \%$ vs. $54.1 \%$; relative benefit $1.08(0.92$, $1.27 \mathrm{p}=0.33)$. Overall survival without BPD at $36 \mathrm{wk}$ in African Americans was better than whites $(37.2 \%$ vs. $25.4 \%$ p = 0.008).

Conclusions Late treatment with surfactant in ventilated preterm infants did not improve survival without BPD at 36 or 40 weeks PMA. Overall better outcome in African-American infants may be due to a racial response to iNO. Pulmonary and neurodevelopmental assessment are on-going.

\section{Cardiac Failure in Congenital Diaphragmatic Hernia: Cause or Consequence?}

\section{0-023 CANDIDATE BIOMARKERS OF PULMONARY HYPERTENSION AND CARDIAC DYSFUNCTION IN CONGENITAL DIAPHRAGMATIC HERNIA}

${ }^{1} \mathrm{~N}$ Patel, ${ }^{2} \mathrm{~F}$ Moenkemeyer. ${ }^{1}$ Neonatal Intensive Care, Royal Hospital for Sick Children, Glasgow, UK; ${ }^{2}$ Neonatology, Royal Children's Hospital, Melbourne, Australia

\subsection{6/archdischild-2014-307384.92}

Background and aims In infants with congenital diaphragmatic hernia $(\mathrm{CDH})$ plasma peptides which mediate, or are produced in response to pulmonary hypertension $(\mathrm{PH})$ and cardiac dysfunction may be useful clinical biomarkers of disease severity. This study investigated correlation between candidate biomarkers and existing measures of oxygenation, $\mathrm{PH}$, and cardiac function in $\mathrm{CDH}$.

Methods Prospective observational study. Plasma samples were obtained for measurement of BNP, NTpro-BNP, VEGF-A, PLGF, and Tropinin1. Concomitant echocardiographic measures of pulmonary artery pressure (derived from TR jet velocity $\left[\mathrm{PAP}_{\mathrm{est}}\right]$; and PDA flow ratio $\left[\mathrm{PDA}_{\mathrm{R}: \mathrm{L}}\right]$ ) and cardiac function (Tissue Doppler Imaging of systolic [S'] and diastolic [E'] velocities and tricuspid valve diastolic flow ratio $\left[\mathrm{TV}_{\mathrm{E}: \mathrm{A}}\right]$ ) were obtained. Oxygenation index was calculated OI.

Abstract 0-023 Table 1 Correlations ( $r$ value) between candidate biomarkers and measures of oxygenation, $\mathrm{PH}$ and cardiovascular function

\begin{tabular}{|c|c|c|c|c|c|c|}
\hline \multirow{3}{*}{$\begin{array}{l}\text { Candidate } \\
\text { biomarker }\end{array}$} & \multicolumn{4}{|c|}{ PH measures } & \multicolumn{2}{|c|}{ Septal TDI velocities } \\
\hline & & & & & IVS S' & IVS E' \\
\hline & 이 & PAP $_{\text {est }}$ & $P D A_{R: L}$ & $\mathrm{TV}_{\mathrm{E}: \mathrm{A}}$ & (systolic) & (early diastolic) \\
\hline BNP & 0.65 & 0.15 & 0.43 & 0.22 & 0.09 & -0.02 \\
\hline NTproBNP & 0.62 & 0.43 & 0.39 & 0.04 & 0.08 & -0.12 \\
\hline Troponin 1 & $<0.01$ & $<0.01$ & 0.26 & -0.30 & 0.26 & 0.04 \\
\hline VEGF-A & 0.64 & 0.18 & 0.10 & -0.30 & -0.11 & -0.18 \\
\hline PLGF & -0.34 & -0.47 & -0.48 & 0.27 & -0.01 & 0.25 \\
\hline
\end{tabular}

Numbers represent $r$ values, significant correlations in bold $(p<0.05)$ 
Results 480 biomarker assays were performed in 80 samples from ten infants. OI correlated positively with BNP, NTproBNP, and VEGF-A, and negatively with PLGF (Table 1). PH measures correlated negatively with PLGF and positively with NTproBNP and Troponin1. Measures of diastolic function correlated negatively with Troponin 1 and VEGF-A, and positively with PLGF.

Conclusions 1) Plasma biomarker analysis is feasible in infants with $\mathrm{PH}$ in $\mathrm{CDH}$.

2) Worsening disease status (impaired oxygenation, PH, diastolic dysfunction) was associated with elevated BNP, NTproBNP, Troponin 1 and VEGF-A, and reduced PLGF.

3) The utility of these peptides as disease biomarkers, prognostic indicators, and their role in disease pathogenesis merits further investigation.

\section{0-024 OUTCOME RESEARCH IN 77 PATIENTS WITH PULMONARY ARTERIAL HYPERTENSION RECEIVING SILDENAFIL: A DOUBLE-BLIND, RANDOMISED CONTROLLED STUDY}

II Palii, ${ }^{2} E$ Vataman, ${ }^{3} \mathrm{~N}$ Revenco, ${ }^{4} \mathrm{~L}$ Maniuc, ${ }^{5} \mathrm{M}$ Vataman, ${ }^{4} \mathrm{O}$ Repin. ${ }^{1}$ Paediatric Cardiology, Institute of Mother and Child, Chisinau, Moldova; ' Laboratory of Heart Failure, Institute of Cardiology, Chisinau, Moldova; ${ }^{3}$ Department of Paediatric SUMF, SUMF Nicolae Testemitanu, Chisinau, Moldova; ${ }^{4}$ Congenital Heart Diseases, Cardiac Surgery Centre, Chisinau, Moldova; ${ }^{5}$ Department of Echocardiography, Diagnostic German Centre, Chisinau, Moldova

\subsection{6/archdischild-2014-307384.93}

Purpose PAH resulting from CHD - a major cause of postoperative morbidity and death. Sildenafil: selective inhibitor of phosphodiesterase-5 - an effective and promising pulmonary vasodilator, with minors reverse effects.

Methods This monocentric, randomised placebo-controlled study evaluated the efficacy, safety, tolerability of oral Sildenafil in children with severe PAH secondary congenital shunts (simple (14 patients), mixed (35), complex (28)). $77 \mathrm{PAH}$ patients (35 - repaired shunts, 31 - palliative, 11 inoperable) assigned to placebo or Sildenafil - dose of $1-2 \mathrm{mg} / \mathrm{kg} / \mathrm{day}$ each $8 \mathrm{~h}$ : 6-12 months. Sildenafil group - 38 (mean age 19, $9 \pm 5$, 3 months: 16 boys/22 girls); placebo -39 (mean age $21,7 \pm 7$, 8 months: 22 boys/17 girls). Research protocol: FC NYHA; 6-min walk test; O2 saturation; echocardiography PAPm, myocardial performance index (MPI/Tei index), right cardiac catheterisation - PVRI; questionnaire for adverse reactions was available.

Results Sildenafil patients improved FC from 3,16 $\pm 0,1-2$, $15 \pm 0,1(\mathrm{p}<0,001)$; effort tolerance $(+152,5 \pm 17,4 \mathrm{~m}-6$ months and $+184,3 \pm 21,2 \mathrm{~m}-12$ months of treatment), $(\mathrm{p}<$ $0,001) ; \mathrm{O}_{2}$ saturation $(+3,1 \pm 0,5 \%)$ but placebo $(+0,6 \pm$ $0,3 \%)$, ( $<<0,001)$; PAPm decreased: $22,0 \pm 2,22$ at 6 months with 19,03 $\pm 2,3 \mathrm{mmHg}-12$ months ( $<<0,001$ ); PVRI decreased: $2,45 \pm 0,19 \mathrm{UWood} \cdot \mathrm{m}^{2}(\mathrm{p}<0,001)$; Tei index with $0,15 \pm 0,01(-31 \%)$ to initial $(\mathrm{p}<0,001)$. In placebo group only PVRI diminished from $6,4 \pm 0,1$ to $5,7 \pm 0,3 \mathrm{UW} / \mathrm{m}^{2}$ (p < $0,05)$. No death in the Sildenafil group, but 5 in placebo.

Conclusions Sildenafil - efficient in treating severe $\mathrm{PAH}$ secondary to congenital shunts, but even more effective in children after cardiac surgery. Sildenafil improves FC, effort tolerability, $\mathrm{O}_{2}$ saturation, $\mathrm{RV}$ global function, diminishing PAPm and PVRI comparing with placebo. Sildenafil has good safety, tolerability, favourable impact on life quality - insignificant adverse reactions.

\section{Cerebral Oxygenation}

\section{0-025 DO SUSTAINED LUNG INFLATIONS DURING RESUSCITATION OF PRETERM INFANTS AFFECT CEREBRAL BLOOD VOLUME AND CEREBRAL REGIONAL OXYGEN SATURATION?}

B Schwaberger, G Pichler, C Binder, N Baik, B Urlesberger. Division of Neonatology, Medical University of Graz, Graz, Austria

\subsection{6/archdischild-2014-307384.94}

Background and aim Sustained lung inflations (SLI) promote lung aeration and alveolar recruitment.

Changes in total haemoglobin $(\Delta \mathrm{cHb})$ and cerebral tissue oxygenation index (cTOI) measured by near-infrared spectroscopy (NIRS) give information on changes in cerebral blood volume (CBV) and regional oxygen saturation, respectively.

Do SLI during resuscitation affect CBV and cTOI?

Methods Preterm infants $\geq 28+0$ and $<34+0$ gestational weeks and need for respiratory support (RS) during postnatal transition were included. Within the first $15 \mathrm{~min}$ of life of each subject $\Delta \mathrm{cHb}$ and cTOI were continuously detected by using 'NIRO200-NX’ (Hamamatsu; Japan).

Two groups were compared based on RS:

SLI group: RS was started by applying 1-2 SLI for $15 \mathrm{sec}$ at 25 $\mathrm{cmH} 2 \mathrm{O}$ and continued by continuous positive airway pressure (CPAP) or positive pressure ventilation (PPV).

Control group: CPAP/PPV depending on respiratory insufficiency. Results 40 preterm infants (23 female) with mean gestational age of $32+1$ weeks ( \pm 3 days) and mean birth weight of $1707 \mathrm{~g}$ $( \pm 470)$ were included. Demographic data did not show significant differences between groups.

Median $\Delta c H b$ was in SLI/control group $-0.38 / 0.20 \mu \mathrm{M} 30$ sec after initializing RS, $-1.33 /-0.43 \mu \mathrm{M}$ after $60 \mathrm{sec}, 3.37 / 2.30$ $\mu \mathrm{M}$ after $2 \mathrm{~min},-0.19 /-0.46 \mu \mathrm{M}$ after $3 \mathrm{~min}, 2.52 / 1.05 \mu \mathrm{M}$ after $5 \mathrm{~min}$ and $2.93 /-4.78 \mu \mathrm{M}$ after $10 \mathrm{~min}$.

Median cTOI increased in SLI/control group from 49/47\% 30 sec after initialising RS to $54 / 50 \%$ after $60 \mathrm{sec}$, to $56 / 51 \%$ after $2 \mathrm{~min}$, to $56 / 58 \%$ after $3 \mathrm{~min}$, to $61 / 61 \%$ after $5 \mathrm{~min}$, and to $65 / 69 \%$ after $10 \mathrm{~min}$.

Conclusion Initialising RS immediately after birth by using SLI in preterm infants did not show significant differences in CBV and cTOI compared to control group.

\section{0-026 INFLUENCE OF PATENT FORAMEN OVALE (PFO) ON REGIONAL CEREBRAL OXYGEN SATURATION DURING IMMEDIATE NEONATAL TRANSITION}

N Baik, B Urlesberger, T Freidl, B Schwaberger, C Binder, G Pichler. Neonatology, Medical University Graz, Graz, Austria

\subsection{6/archdischild-2014-307384.95}

Background During postnatal transition there is a significant association between regional cerebral oxygen saturation of the brain and the shunt via the ductus arteriosus (DA). The influence of the patent foramen ovale (PFO) on the cerebral regional saturation remains as a question.

Aim The aim of the study was to investigate the influence of the PFO on the cerebral oxygen saturation, measured by near-infrared spectroscopy (NIRS) after 15 min of neonatal transition.

Methods Observational study. Term neonates ( $>37$ weeks of gestational age) after elective caesarian section and without any 